\title{
Entre o Índico e o Atlântico: Incursões literárias de Maria Archer
}

\section{Elisabeth Batista ${ }^{1}$}

RESUMO: De 1955 a 1977, Maria Archer (1899-1982), escritora portuguesa veio cumprir um longo exílio em terras brasileiras. O objetivo primeiro deste trabalho é apresentar as contribuições desta escritora para a imprensa de Língua Portuguesa.

ABSTRACT: From 1955 to 1977 the Portuguese writer Maria Archer (1899-1982) lived a long time exiled in Brazil. The main objective of this work is to present the contributions of this female writer for the press into Portuguese language.

PALAVRAS-CHAVE: Maria Archer; mulher, literatura; exílio; imprensa. KEYWORDS: Maria Archer; woman, literature; exile; press.

\section{"A minha obra literária tem sido norteada pelo princípio vital de rebater o conceito arcaico da inferioridade mental da mulher".}

(Archer, 1952, p.5)

A literatura de autoria feminina nos países que se comunicam através da língua portuguesa conta com excelentes representantes. Um breve olhar sobre essa produção revela que a partir da última metade do século passado, notadamente nas décadas de 40 e 50 , ela veio gradativamente chamando a atenção de pesquisadores e conquistando, cada vez mais, o prestígio do público-leitor. Não há como negar a contribuição feminina na literatura contemporânea. Grande tem sido o número de escritoras que vem se destacando pelo inegável talento literário na poesia, na prosa e na narrativa de ficção em Portugal, tais como Agustina Bessa-Luís, Lídia Jorge, Marta de Lima, Clara Pinto Correia, Irene Lisboa, Fernanda Botelho, Maria Judite de Carvalho e outras.

A escritora portuguesa Maria Archer, no entanto, parece encontrar-se em quase completo esquecimento. Tal constatação é surpreendente, sobretudo após tomar conhecimento da variedade e do grande número de livros e artigos por ela escritos, além de uma série de conferências que também proferiu. É farto o repertório de sua produção literária laborada entre 1935 e 1963. Os seus livros, entretanto, com exceção de Ela é

${ }^{1}$ Doutoranda em Estudos Comparados de Literaturas de Língua Portuguesa, FFLCH-USP. Pesquisa: $O$ desdobramento da condição feminina no universo narrativo: Uma leitura de Lygia Fagundes Telles e Maria Emília Archer. 
apenas mulher, reeditado em 2001, e Nada lhe será perdoado, reeditado em 2006, só podem ser encontrados, atualmente, nos alfarrabistas.

A pesquisa que desenvolvemos tem por objetivo abordar aspectos fundamentais da vida e obra de Maria Archer, exilada no Brasil no período de 1955 a 1977. Em seu ensaio "Reflexões sobre o exílio" (2003), Edward Said - ele próprio representante da situação de diáspora vivida por muitas pessoas no século XX - afirma que esse século é "com efeito, a era do refugiado, da pessoa deslocada, da imigração em massa" (p.47).

Publicou seu primeiro livro aos 36 anos. Editado em Luanda, em parceria com o escritor Pinto Quantim Graça, o volume é constituído de duas novelas. A de Maria Archer Três mulheres - de cunho sentimental, e a de Pinto Quantim - A lenda e o processo do estranho caso de "Pauling" - do gênero policial. Escreveu, também, em linguagem bem acessível, própria para o público infanto-juvenil, o livro de aventuras infantis Viagem à roda de África, que lhe rendeu o prêmio Maria Amália Vaz de Carvalho em 1938. A África foi, ainda, a base para uma série de seis livros na Coleção Cadernos Coloniais, entre 1936 a 1938.

Nascida na Freguesia das Mercês, em Lisboa, na madrugada do dia 04 de Janeiro de 1899, filha de João Baltazar Moreira Junior e de Cipriana Archer Eyrolles Baltazar, Maria Archer foi viver em Moçambique com a família, em 1910. Eram ao todo seis filhos; Maria Archer a mais velha deles. A transferência se deu em razão das contingências profissionais do pai da escritora que passou a desempenhar a função de gerente de agência bancária. Esta foi a sua primeira viagem à África. Em sua obra intitulada Brasil, Fronteira da África (1963) a autora relata essa experiência:

No $1^{\circ}$ quartel deste século, era eu menina, meu pai foi colocado na agência de um banco em Moçambique. Daí derivou a minha odisséia de africanista. Indo e vindo, passando uns tempos em Portugal e outros em África, foram-se quatorze anos da minha vida em terras tropicais. (Archer, 1963, p.121).

Archer veio terminar a escola primária já com dezesseis anos de idade, no colégio europeu. O contínuo convívio com pessoas adultas, por quem ela tinha clara preferência, contribuiu certamente para o amadurecimento precoce das suas idéias e, conseqüentemente, para o exercício fluente da sua escrita. Mulher de cultura exuberante, a escritora foi praticamente uma autodidata, pois até para terminar o primário ela precisou implorar aos 
pais que acreditavam, segundo o pensamento da época, que os conhecimentos já adquiridos eram suficientes para uma jovem mulher.

A estada em Moçambique estende-se até 1913. Passaram-se três anos naquela que Maria Archer chamou de "ilha de coral branco". No ano seguinte, 1914, a família regressou para Portugal, vivendo uma temporada na Linha de Caiscais. Dirigem-se depois para Algés e, posteriormente, para Santo Amaro, altura em que Maria Archer teria concluído aquilo que equivale no Brasil à quarta série do ensino fundamental.

De 1916 a 1918 deslocam-se uma vez mais para a África. Outra "colônia" marca o destino de Maria Archer: à "Guiné Maravilha”, “a verdadeira África Maravilhosa” (Archer, 1940, p. 43). Na Guiné ficaram um ano em Bolama e outro em Bissau.

Em sua obra Roteiro do mundo português (1940) encontramos o registro da aproximação do arquipélago dos Bijagós e as primeiras impressões da escritora sobre a paisagem e os nativos avistados a bordo.

Para quem chega do mar à Guiné o assombro começa mal a terra se avista. Os Bijagós surgem no horizonte, deixam-nos aproximar e nos envolvem. É formado por um numeroso arquipélago de ilhas e ilhéus rasteiros à água, verdes e misteriosos, ricos de uma exuberância tropical de matas ondulantes e cerradas. $\mathrm{O}$ navio sinua entre as suas ilhas até atingir o porto de Bolama, ou o de Bissau, e despejar o seu carreto de cargas ou passageiros. (Archer, 1940, p.44).

Em 1921 o pai foi trabalhar para o Banco Nacional Ultramarino, em Faro, ao sul de Portugal. É aí que a escritora recebe proposta de casamento do jovem português Alberto Teixeira Passos, pretendente que conheceu ainda na ilha de Moçambique onde, na altura desempenhava a função de tesoureiro de uma agência bancária. O casamento acontece no dia 29 de agosto de 1921 e o jovem casal passa a viver em Ibo-Moçambique, vivendo aí durante cinco anos. Alberto, que na altura tem 31 anos, retorna à sua função no mesmo banco. Maria Archer, na época tem 22.anos.

Cinco anos depois, durante a ditadura militar que se seguiu ao golpe militar de 1926, data do início da primeira legislatura da Assembléia Nacional do Estado Novo, sobreveio a grande crise política e econômica. O marido de Maria Archer vem a perder o emprego e ambos retornam à cidade de Faro, ao sul de Portugal. Ali vivem os últimos anos de vida conjugal. O divórcio veio dez anos após a união - em 21 de março de 1931 já estavam oficialmente separados. Após a separação, a escritora vai para Angola viver com 
os pais, ainda que a separação fosse uma atitude inusitada para a tradição familiar. Durante quatro, cinco anos reside em Luanda, consolidando, a partir daí, sua carreira literária.

Ao ingressar nessa nova etapa de vida é que Maria Archer lança, em 1935, ainda em Luanda, a novela Três mulheres, a que já nos referimos, No mesmo ano publica em Lisboa África Selvagem. Folclores dos negros do Grupo “Bantu”, pela Guimarães e Cia. Editores. Com este trabalho a escritora ingressa no universo da literatura voltada para a temática africana.

Importa, assim, mencionar que o regresso da escritora a Lisboa, após uma experiência de vida de vários anos na África de expressão portuguesa, foi contemporâneo ao período de produção e circulação intensa de práticas culturais expressivas em torno das colônias. Após o regresso de Luanda a escritora participou de conferências e palestras ultramarinas, das salas da SGL (Sociedade Geográfica de Lisboa) aos microfones da Emissora Nacional, em liceus da capital e estabelecimentos militares. A sua presença era regular, também, em jornais e revistas. Aliás, muitos de seus textos de temática africana aparecem inicialmente na imprensa periódica lusitana.

Esse detalhe da biografia de Maria Archer ajudará a compreender a sua vasta bibliografia de temática colonial publicada ora em livros, ora em periódicos, ora, ainda, em revistas especializadas como $O$ mundo português, Portugal colonial e Ultramar. Assim, a consolidação de sua atividade como escritora e jornalista de matérias coloniais foi fruto do interesse de uma época em que viu reunidas as condições necessárias à produção e ao consumo daquele gênero de literatura.

Efetivamente, após ter lançado África Selvagem, em 1935, publica, no ano seguinte, três volumes da Coleção Cadernos Coloniais: Sertanejos, Singularidades dum país distante e Ninho de bárbaros. A recepção crítica da obra África Selvagem, sua estréia no domínio da literatura colonial, não poderia ter sido mais satisfatória: "excepcional revelação literária", obra suficiente "para impor Maria Archer como escritora, para consagrar os seus dotes de narradora perfeita"; "maravilhoso repositório do folclore negro" foram alguns dos comentários surgidos em alguns dos órgãos da imprensa escrita metropolitana.

Segue uma vida de intensa produção intelectual. Em 1937 foi publicado o Angola filme, o quarto dos seis volumes publicados na Coleção Cadernos Coloniais. Em 1938, a Editorial Cosmos lançou dois "cadernos" de autoria da escritora: Colônias piscatórias em Angola e Caleidoscópio africano. Nesse mesmo ano é que a autora publica o premiado Viagem à roda da África, romance de aventuras a que acima nos referimos. 
Dois anos mais tarde Maria Archer entrega ao público leitor Roteiro do mundo português (1940), obra que percorre as províncias ultramarinas portuguesas em África e no Oriente. Este título constitui claramente uma alusão à exposição do mundo português. Publica ainda: Há dois ladrões sem cadastro (1940), Fauno sovina (1941), Memórias da linha de Cascais (1943), Os parques infantis (1943), Ela é apenas mulher, 1º. ed. Lisboa, em parceria com António Maria Pereira (1944), Ela é Apenas Mulher, 20ed. (1944), Aristocratas (1945), Eu e elas, Apontamentos de Romancista (1945), Aristocratas, $2^{\circ} \mathrm{ed}$. (1946). Além de ser o seu único meio de sobrevivência, a sua obra tem também alguma relação com a sua vida. A obra Aristocratas (1945), por exemplo, marcou a degradação de suas relações com a família. É uma espécie de narrativa autobiográfica, não bem aceita, aliás, pelo seu núcleo familiar. A autora vai arcar com as conseqüências da opção pela literatura: O isolamento faz-se sentir desde então.

Outras obras vêm a seguir: A Morte veio de madrugada (1946), Casa sem pão (1947), uma nova edição de Há de haver uma lei, $2^{\circ}$ ed., (1949) e as peças de teatro: Alfacinha - comédia em 1 ato para uma só personagem, publicada no Sol entre 12 e 26 de fevereiro de 1949; Isto que chamam amor e Numa casa abandonada - dramas em um ato para uma só personagem; $O$ poder do dinheiro, comédia em 3 atos; $O$ leilão, drama em 3 atos.

Ainda publicou: Há de haver uma lei, $3^{\circ}$ ed. (1950), O mal não está em nós (1950), Filosofia duma mulher moderna (1950), Roteiro do mundo português, $2^{\circ} \mathrm{ed}$. revista e ampliada (1950), Bato às portas da vida (1951), Bato às portas da vida, 2ed. (1952), Ela é apenas mulher, 3ed. (1952), Nada lhe será perdoado (1952), Nada lhe será perdoado, $2^{\circ}$ ed. (1954), A primeira vitima do Diabo (1954), A primeira vitima do Diabo, $2^{\circ} \mathrm{ed}$. (1954).

Aproveitando muitos textos de Roteiro do Mundo Português a escritora lança, ainda Herança Lusíada (s.d), pela editora Coleção Peninsular. Esta obra tem um diferencial: um prefácio do sociólogo brasileiro Gilberto Freyre. O intelectual destaca o "talento literário" de Maria Archer, sua "qualidade de observação", seu "poder de análise" e o "gosto pelo estudo do que do ponto de vista europeu é exótico, pitoresco ou bizarro".

No artigo "Maria Archer", de Raul Rego, datado de 02 de fevereiro de 1982, para o Diário Popular, o jornalista faz um breve estudo da atuação sócio-política da escritora em Portugal. Escrito dias após sua morte, o jornalista comenta como a sua postura anticonformista a "afastou logo de muitos meios oficiais e de muitos salões de tertúlias, arrastando-a para os contatos com a oposição". E prossegue: "Ela era uma mulher livre, 
escritora de garra, senhora de si e impondo-se pelo talento", o que na altura, não agradava a muitos, a ponto de sua obra Ida e volta de uma caixa de cigarros (1938) ser apreendida.

Em 1945, segundo relata-nos o artigo de Raul Rego para o Diário Popular, Maria Archer adere ao $\operatorname{MUD}^{2}$ (Movimento de Unidade Democrática), organização política que surgiu em oposição ao Estado Novo no contexto do final da Segunda Guerra Mundial. Em 1947 lança Casa sem pão, que, entretanto, fica apreendido, pelas malhas sombrias da censura e falta de liberdade pelo regime, por 20 anos.

O cerceamento da liberdade de pensamento sob a vigência do Estado Novo, o isolamento social, a perseguição da PIDE, as sucessivas apreensões de seus livros Ida $e$ volta de uma caixa de cigarros (1938 e 1939) e Casa sem pão (1947) e, conseqüentemente, a retirada de seus meios de subsistência já eram razões suficientes para forçarem-na a abandonar Portugal. Maria Archer, a exemplo de vários intelectuais portugueses, deixa o país, conforme registra Miguel Urbano Tavares - ele também representante da diáspora em seu artigo "Portugueses hostilizados numa terra fraterna", veiculado no dia 21 de abril de 2000, no Diário de Notícias, de Lisboa:

[..].Mas foi a partir do final dos anos 50 que a corrente dos exilados políticos adquiriu um volume torrencial. Ao Brasil chegaram em diferentes anos e na seqüência de acontecimentos e perseguições políticas de natureza também diferente, muitos portugueses que, em permanências de longa ou breve duração, marcaram com sua presença a vida brasileira. [...].Outros nomes a lembrar são os escritores Adolfo Casais Monteiro, Carlos Maria Araújo, Sidónio Muralha, Jorge de Sena, Castro Soromenho, Maria Archer, Mário Henrique Leiria [...]. (Diário de Notícias, 21-04-2000).

Em Portugal Maria Archer foi escritora e jornalista durante os anos em que o Estado Novo queria a mulher em casa. A situação portuguesa na altura era francamente hostil a expressões do pensamento crítico e opiniões divergentes e, sobretudo, advindos de uma mulher. $\mathrm{O}$ contexto era hostil à presença da escritora, pois todo o país provinciano e moralista encontrava-se em plena ditadura fascista. Num tempo assim tão áspero, gestos que hoje nos parecem simples exigiam grande dose de ousadia.

\footnotetext{
${ }^{2}$ Com a vitória dos Aliados e a conseqüente democratização de toda a Europa Ocidental, o regime fascista de Salazar ficou numa posição isolada e bastante incômoda em nível internacional, o que o levou a "simular" uma política de abertura. A oposição organiza-se e a 8 de Outubro de 1945 nasce, com autorização do Governo, numa reunião efetuada no Centro Escolar Republicano Almirante Reis, em Lisboa, o MUD.
} 


\section{A vinda para o Brasil}

"Navegar é preciso. Viver não é preciso".

(Fernando Pessoa)

A lusitana viajada, jornalista, tradutora, conferencista, que viveu em Angola, GuinéBissau, Niassa, Luanda, transfere-se para esta outra margem do Atlântico a partir de 15 de julho de 1955. Seis meses mais tarde, em entrevista ao jornal carioca Diário de Notícias, na edição datada de 15.01.1956, descreve os tempos ásperos e o ambiente hostil e opressivo de Portugal, falando do motivo do seu exílio no Brasil:

Vim para o Brasil, tendo chegado dia 15.07.1955, porque já não podia viver em Portugal. A ação da censura asfixiou-me e tirou-me os meios de vida. Apreenderam-me dois livros publicados, assaltaram-me com policiais a casa e levaram-me um original que ainda estava escrevendo, violência inédita em países de civilização européia. (Diário de Notícias, 15-01-1956).

No Brasil, aonde veio cumprir um largo período do exílio, Maria Archer foge ao modelo cultural que corresponde ao padrão da feminilidade previsto para a mulher portuguesa na época do Estado Novo, padrão que se apoiava na teoria de que a dependência e a subserviência são inerentes à condição feminina. Escreveu e publicou obras voltadas para a divulgação da cultura dos países em que viveu e que mantêm o português como língua de comunicação.

Foi além, produziu artigos em jornais, sementes de contestação ao domínio salazarista em Portugal, discursos, crônicas, palestras radiofônicas. Assim, desta outra margem do Atlântico, escreveu para alguns jornais como O Estado de São Paulo, Semana Portuguesa e Portugal Democrático. Nas duas décadas que aqui viveu produziu artigos que contribuíram vivamente para a composição do movimento de resistência ao regime conservador e autoritário vigente em Portugal. Nasce dessa iniciativa conjunta com vários exilados portugueses o órgão de imprensa Portugal Democrático (1955-1974), que pretendia divulgar a situação que se vivia em Portugal e seria a concretização da aspiração de se constituir um grupo de anti-salazaristas a partir do exílio.

Com base em sua vivência e conhecimento sobre a África, já assinalada, Maria Archer, na época em que esteve radicada no Brasil, publicou: 
Terras onde se fala português (1957), roteiro no qual apresenta compreensiva síntese sócio-histórico-geográfica dos territórios africanos que mantém o português como língua de comunicação; Os últimos dias do fascismo português, da editora Liberdade e Cultura. A $1^{\text {a }}$ edição, publicada em 1959, foi de três mil exemplares. Trata-se dos apontamentos tomados durante as audiências do julgamento do Capitão Henrique Galvão, uma espécie de memórias do processo político, do $1^{\circ}$ Tribunal Militar Territorial (Santa Clara) em Lisboa, em Dezembro de 1952.

África sem luz (1962), coletânea de contos e narrativas africanas, densas de sortilégios, em que nos apresenta um mundo poderoso e ingênuo, forte e primitivo; Brasil, fronteira da África (1963), em que apresenta aos brasileiros a África de expressão portuguesa, sobretudo Angola em guerra pela independência do colonialismo salazarista. Conclama ao Brasil para que assuma o papel de "paladino" da Língua Portuguesa e impeça o aniquilamento do idioma comum aos três países, assim como também da cultura, sobretudo em Angola, país em luta pela construção de uma identidade nacional.

A produção da escritora, laborada no Brasil entre 1955 e 1963, dialoga entre si e com outras esferas da produção de conhecimento como a história, a geografia, a sociologia e a antropologia, numa feliz expressão da riqueza do pensamento crítico e de olhar atento sobre a contemporaneidade. Nas suas produções, os encontros África/Brasil/Portugal passam a ser de interação pelas experiências compartilhadas e, nas suas peculiaridades, tratam da maneira como a Europa, o Continente Africano e a América do Sul se vêem, se imaginam e se mesclam, pois "a convivência com o diverso leva ao diálogo com o outro eu" (ABDALA JR., 2003, p. 55).

Em meio ao cenário dominado hegemonicamente pelas vozes masculinas que marcaram a produção de conhecimentos na época, estamos convencidos da importância de dar a conhecer as contribuições de Maria Archer para a imprensa de língua portuguesa. Vale a pena examinarmos, através da reconstituição de parte da sua instigante biografia, os fatos de sua vida ainda não difundidos, as razões do seu exílio, a escolha do Brasil como destino.

O estudo aprofundado de sua contribuição para a imprensa no Brasil nos ajudará a entender a forma como a escritora, ao empreender o deslocamento territorial entre os continentes afro-luso-brasileiro, se adapta à realidade cultural dos três continentes em questão. Ajudará, além disso, a compreender como se deu o encontro do olhar estético na 
captação da "alma de um povo" através de suas incursões literárias entre o Índico e o Atlântico.

\section{Referências bibliográficas}

ABDALA JR., Benjamin. De vôos e ilhas: literatura e comunitarismos. São Paulo: Ateliê Ed., 2003.

"Globalização e novas perspectivas comunitárias." In: ABDALA JR. Benjamin \& SCARPELLI, Marli F. (orgs.) Portos flutuantes: trânsitos ibero- afro-americanos. São Paulo: Ateliê Editorial, 2004.

. "Um ensaio de abertura: mestiçagem e hibridismo, globalização e comunitarismos". In: ABDALA JR. Benjamin (org.). Margens da cultura: mestiçagem, hibridismo \& outras misturas. São Paulo: Boitempo Editorial, 2004.

ARCHER, Maria. "Revisão de Conceitos Antiquados". In: Ler (7). Lisboa. Out. 1952, p.5.

ALDONIO, Gomes. Fernanda CAVACAS. Dicionário de autores de literaturas africanas de Lingua Portuguesa. Lisboa: Editorial Caminho, 1997.

BOTELHO, Dina Maria dos Santos. Ela é apenas mulher. Universidade Nova de Lisboa. Dissertação de Mestrado em Estudos Anglo Portugueses, Faculdade de Ciências Sociais e Humanas, Lisboa, 1994.

FERREIRA. Ana Paula. 'Continentes negros' com nome de Portugal: O 'Feitiço' colonialista da Maria Archer. Discursos Estudos de Língua e Cultura Portuguesa. Literatura, Nacionalismos, Identidade. 1996, nº 13, p.85-98.

LOPES, Oscar. História da Literatura Portuguesa. As correntes contemporâneas. Vol. 7. Lisboa: Alfa, 2002.

MARTINS, Leonor Pires. Menina e moça em África: Maria Archer e a Literatura Colonial Portuguesa. http://www.lusotopie.sciencespobordeaux. fr/somma.2005.htm, p. 77-91.

OLIVEIRA, Américo Lopes de. Dicionário de mulheres célebres. Porto: Lello e Irmão, 1998. p. $73-$ 4.

REGO, Raul. "Maria Archer". In: Diário Popular, 02 de fevereiro de 1982.

SAID, Edward. Reflexões sobre o exílio e outros ensaios. São Paulo: Cia. Das Letras, 2003. 